
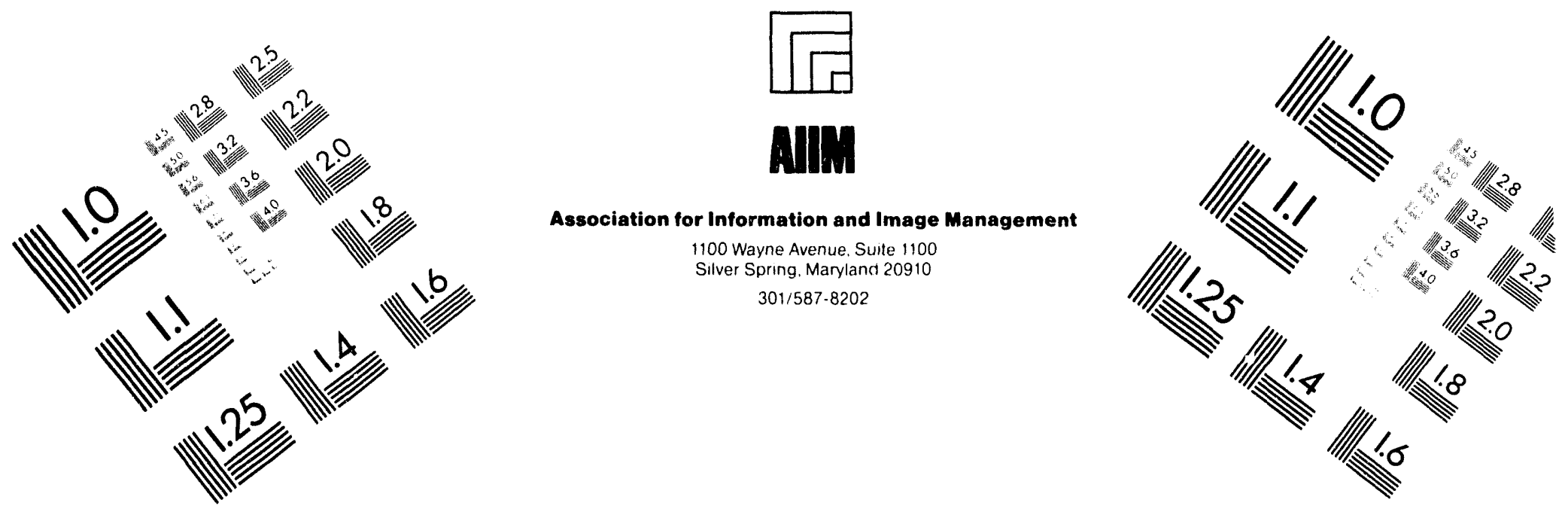

\title{
Centimeter
}

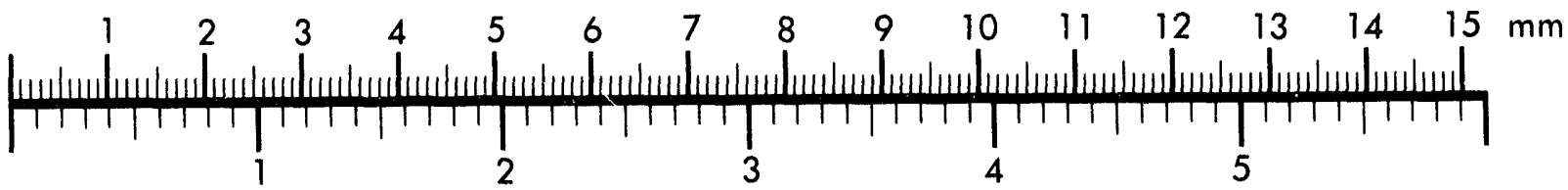

Inches
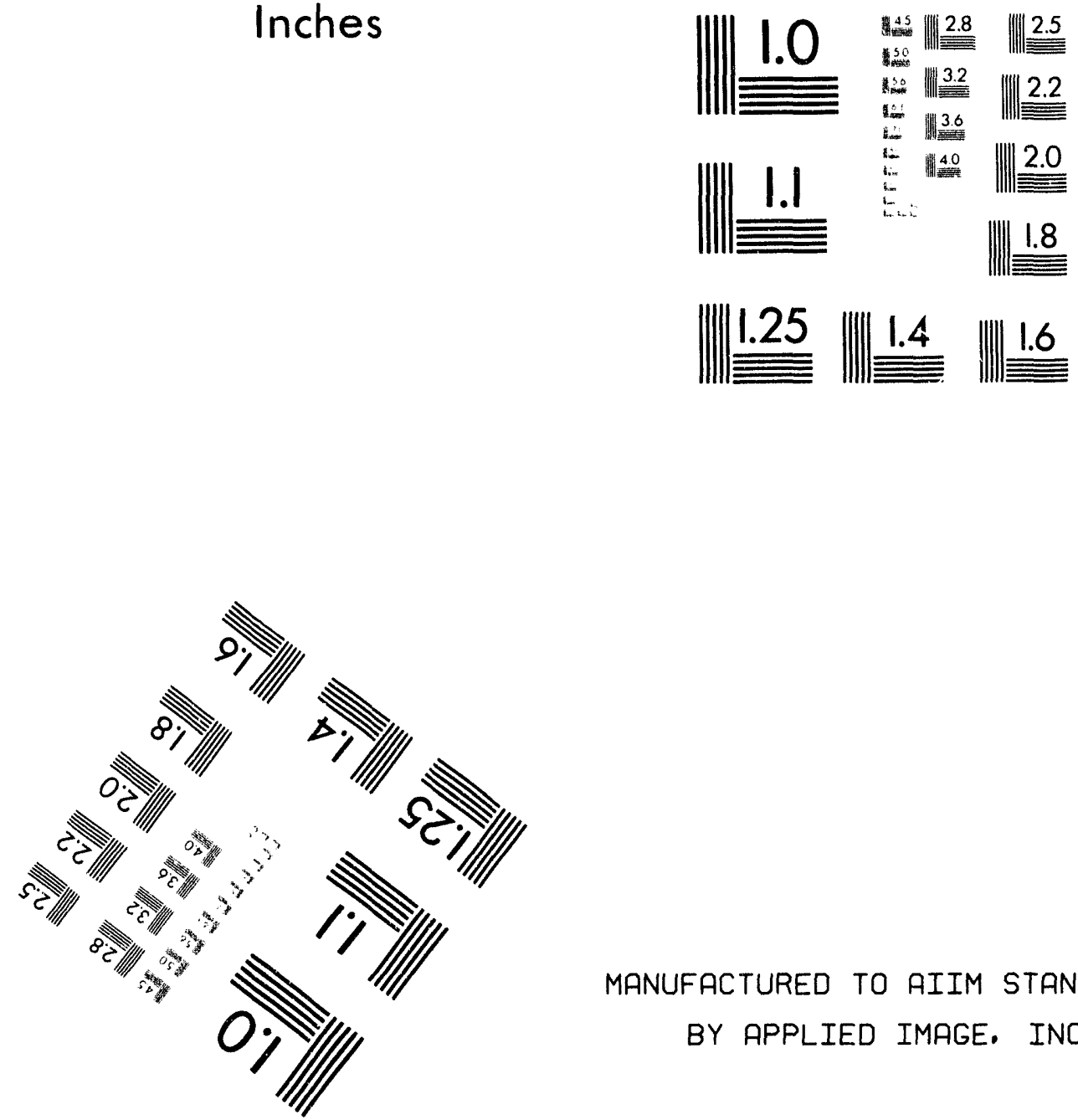

MANUFACTURED TO AIIM STANDARDS

BY APPLIED IMAGE. INC.

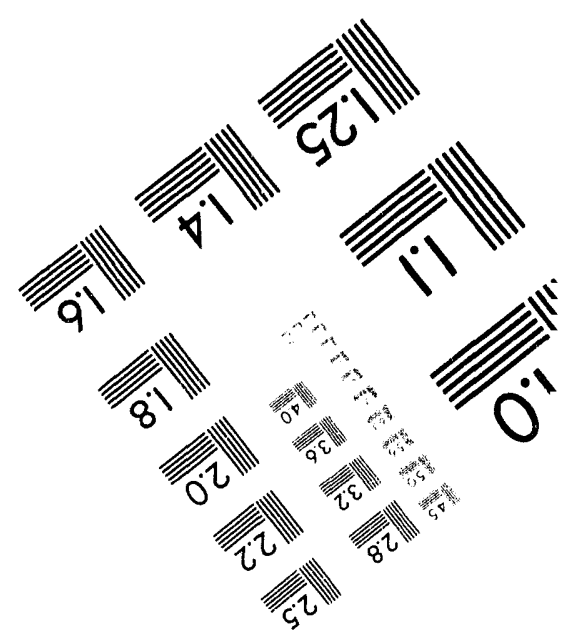



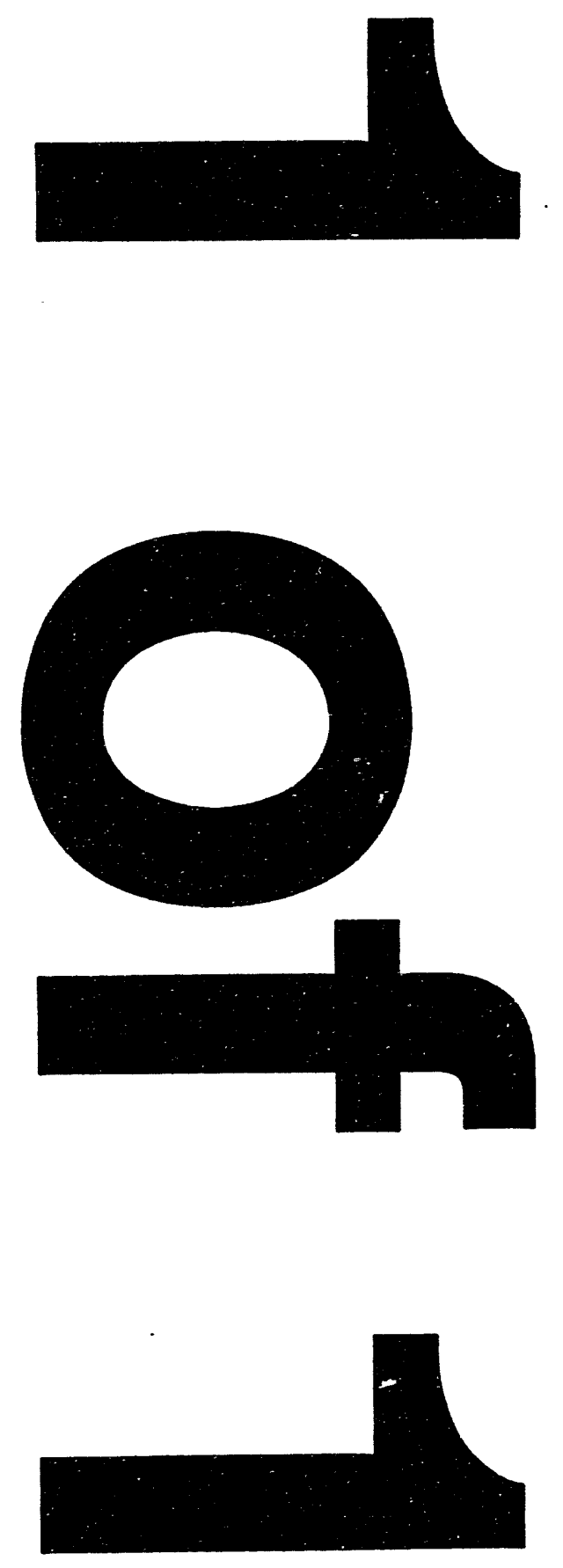
$\frac{600}{5.35} \cdot 9495(2)$

U.S. Department of Energy

Ofice of Environmental Guidance

RCRA Information Briof

EH-231-0380494 (April 1994)

\section{Manifest Requirements}

010,01010

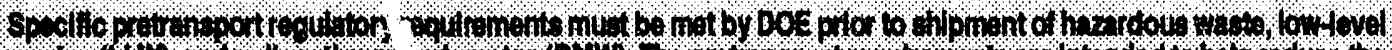

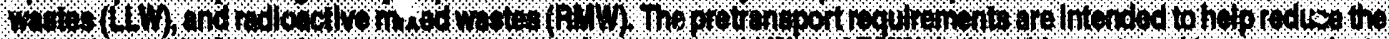

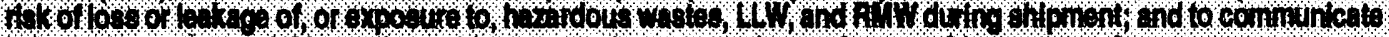

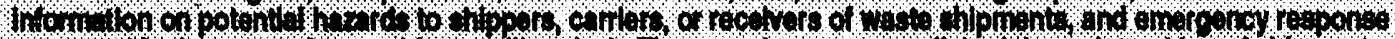

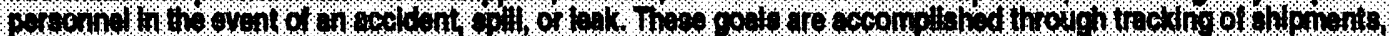

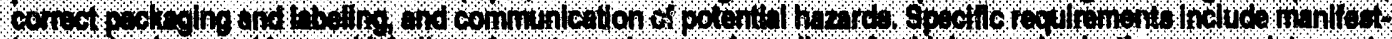

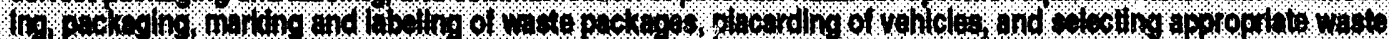

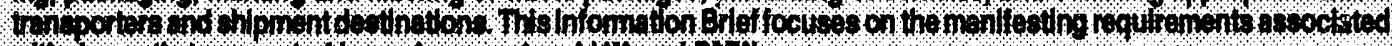

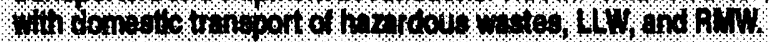

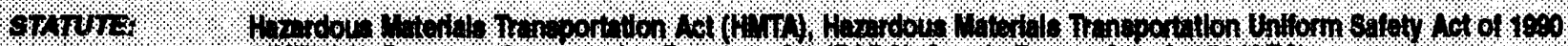

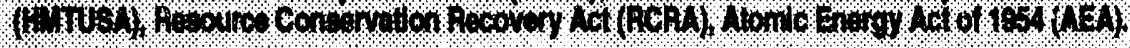

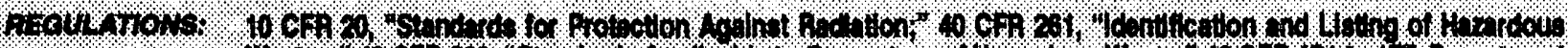

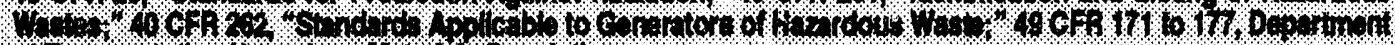

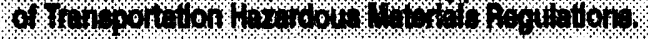

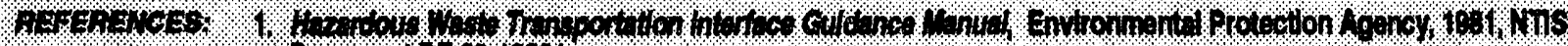
$0.01,100101$

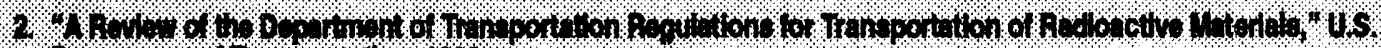

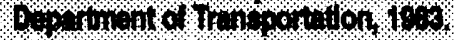

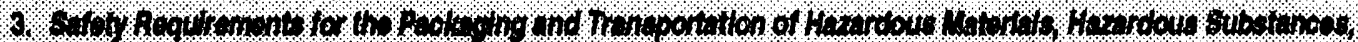

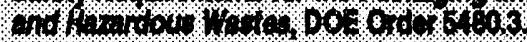

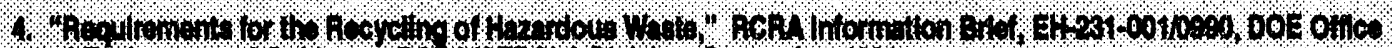

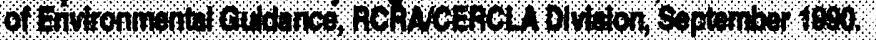

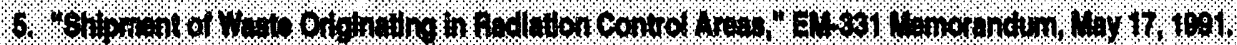

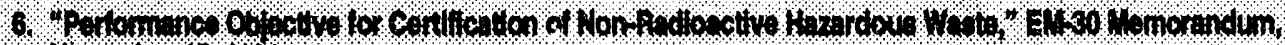
$12411,15,100$

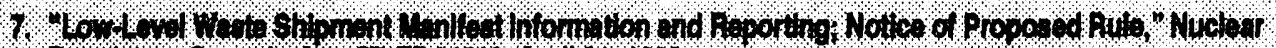
R.

\section{What is a hazardous waste under RCRA?}

RCRA regulations in 40 CFR 261.3 identify those solid wastes that must be managed as hazardous wastes. A solid waste is a hazardous waste if it is not excluded from the hazardous waste regulations, and it is either of the following:

a listed waste, which is included in one of four lists developed by EPA and contained in 40 CFR 261.31 through 261.33, or

a characteristic waste, which means that it exhibits one or more of four characteristics identified in 40 CFR 261.21 through 261.24-"ignitability," "corrosivity," "reactivity," and "toxicity."

For further information concerning identifying a hazardous waste, please refer to Reference 4.

\section{What is a hazardous waste manifest and how is it used?}

RCRA and DOT regulations require that a generator who transports or solicits others for the transportation of hazardous wastes to an off-site facility for treatment or disposal must prepare a hazardous waste manifest. There are two types of hazardous waste manifests; the uniform hazardous waste manifest (EPA Form 8700-22) and State hazardous waste manifests. One of the purposes of the manifesting system is to allow the generator; regulatory agencies; transporters; treatment, storage, or disposal facilities (TSDFs); and other interested parties to keep track of the transportation of hazardous waste from the generator's facility to an off-site treatment or disposal facility. The manifest is an important feature of RCRA's "cradle to grave" system. The process for transportation of hazardous waste from a generator to a TSDF consists of the following:

$\checkmark$ The generator must sign and date the original manifest. When the primary transporter accepts the hazardous waste, the transporter, before leaving the generator's property, must sign and date the manifest and provide one copy to the generator.

口 If the primary transporter transfers waste to another transporter, the secondary transporter must sign and date the manifest and provide a copy to the primary transporter.

Upon arrival at the TSDF, the transporter must provide the manifest to the TSDF; if the TSDF accepts the waste, they must sign and date the manifest and provide a copy to the transporter. The TSDF must return a copy of the manifest to the generator within 30 days [40 CFR 264.71(b)(4)]. If the TSDF does not accept the waste, the transporter either transports the hazardous waste to an alternative TSDF or

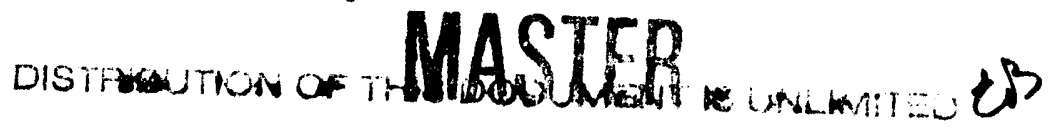


back to the generator. If the generator does not receive a copy of the manifest within 35 days of the date the waste was accepted $b y$ the initial transporter, the generator must contact the designated facility or the transporter to determine the status of the hazardous waste. If the generator does not receive a copy of the manifest within 45 days of the date the waste was accepted by the initial transporter, the generator must submit an exception report to the EPA Regional Administrator or the authorized State [40 CFR 262.42(b)].

Manifests are used to provide records of shipments. A generator must keep a copy of each manifest for three years.

\section{Under what circumstances should a uniform hazardous waste manifest or a State hazardous waste manifest be used?}

The type of manifest is dependent upon whether the generator's State or the consignee's State has its own manifest. Provided below are four scenarios that a generator may encounter when transporting hazardous wastes interstate:

- If neither the consignee's State nor the generator's State have their own hazardous waste manifests, then the generator uses the uniform hazardous waste manifest.

口 If the consignee's State has its own hazardous waste manifest and the generator's State does not, then the generator uses the consignee's State hazardous waste manifest.

- If the consignee's State does not have its own hazardous waste manifest and the generator's State does, then the generator uses the generator's State hazardous waste manifest.

- If the consignee's State and the generator's State have their own hazardous waste manifests, then the generator usually uses the generator's State hazardous waste manifest. Both States should be contacted in this situation to determine which manifest to use.

\section{How are hazardous waste manifests prepared?}

The appendix to 40 CFR 262 contains instructions for preparing uniform hazardous waste manifests. The required forms are EPA Form 8700-22 (the Uniform Hazardous Waste Manifest) and EPA Form 8700-22A (the continuation sheet). DOT manifesting regulations are contained in 49 CFR 172.205. Appropriate State regulatory agencies should be contacted to obtain instructions for preparing State hazardous waste manifests.

\section{What is LLW?}

All radioactive wastes that are not classified as high-level wastes, transuranic wastes, spent fuels, or uranium and thorium tailings are classified as LLW (DOE Order 5820.2A).

\section{What documents are required for the shipment of LLW?}

Presently, there is no uniform low-level radioactive waste manifest, but there are NRC manifesting requirements. The shipment of LLW must be accompanied by documents that contain information required by NRC, DOT, and applicable States. Some commercial LLW disposal facilities have their own unique manifests that contain all NRC, DOT, and State requirements for shipment of LLW.

The number and types of documents required may vary for the transportation of LLW from one DOE facility to another. Regardless of the types of documents used, the manifesting requirements for transportation of LLW contained in 10 CFR 20, 49 CFR 172, and applicable State regulations must be included in the manifesting documents. One of the purposes of NRC manifesting requirements is to track LLW from the point of generation to the final disposal site. The tracking process for the transportation of LLW from a generator to an NRC-licensed disposal facility is:

a The generator certifies that the wastes transported are properly classified, described, packaged, marked, and labeled according to DOT and NRC regulations. The generator keeps one copy of the manifesting document and forwards another copy to the licensed transporter when the wastes are transported off site.

- Upon arrival at the NRC-licensed land disposal facility, the transporter forwards a copy of the manifesting documents to the facility. Upon receipt of the wastes, the facility has one week to return a signed copy of the manifesting documents to the generator. If the generator does not receive a copy of the manifesting documents within 20 days, the generator must perform an investigation to determine the status of the LLW shipment.

DOT shipping-paper requirements for the transportation of radioactive material are contained in 49 CFR 172 Subpart C. NRC manifesting and tracking requirements are contained in Appendix F to 10 CFR 20.1001 through 20.2401. For State requirements, the consignment facility or State regulatory agency should be contacted to obtain required manifesting documents.

On April 21, 1992, NRC proposed new LLW regulations that would improve LLW manifesting information and reporting. Proposed changes irclude the following:

$\square$ requiring use of new NRC manifest forms,

$\checkmark$ allowing forwarding of certain portions of the paperwork to NRC sn that not all of the papers will have to accompany the LLW package,

requiring verification of shipments, and requiring electronic storage of copies of the manifests and related records by LLW land disposal facility operators.

\section{What is RMW and what manifests are required for the transportation of RMW?}

RMW has a hazardous component which is regulated under RCRA and a radioactive component which is regulated under the AEA. If a waste is considered an RMW, documents containing all information required by NRC, DOT, and applicable States for the transportation of LLW waste and a hazardous waste manifest are required to accompany the shipment from the generator to the disposal or treatment facility.

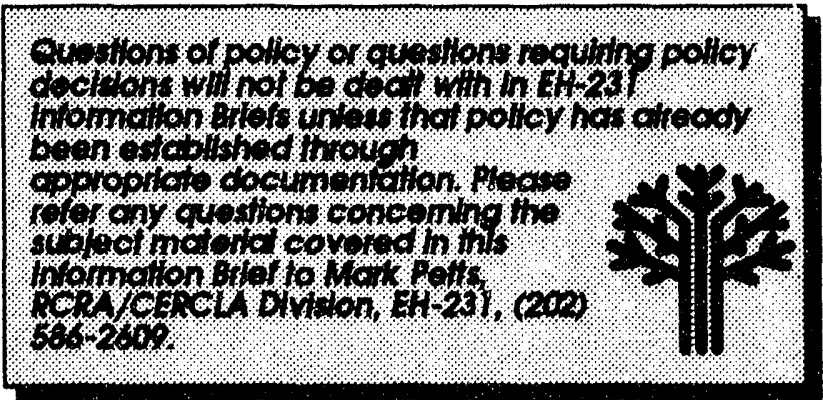



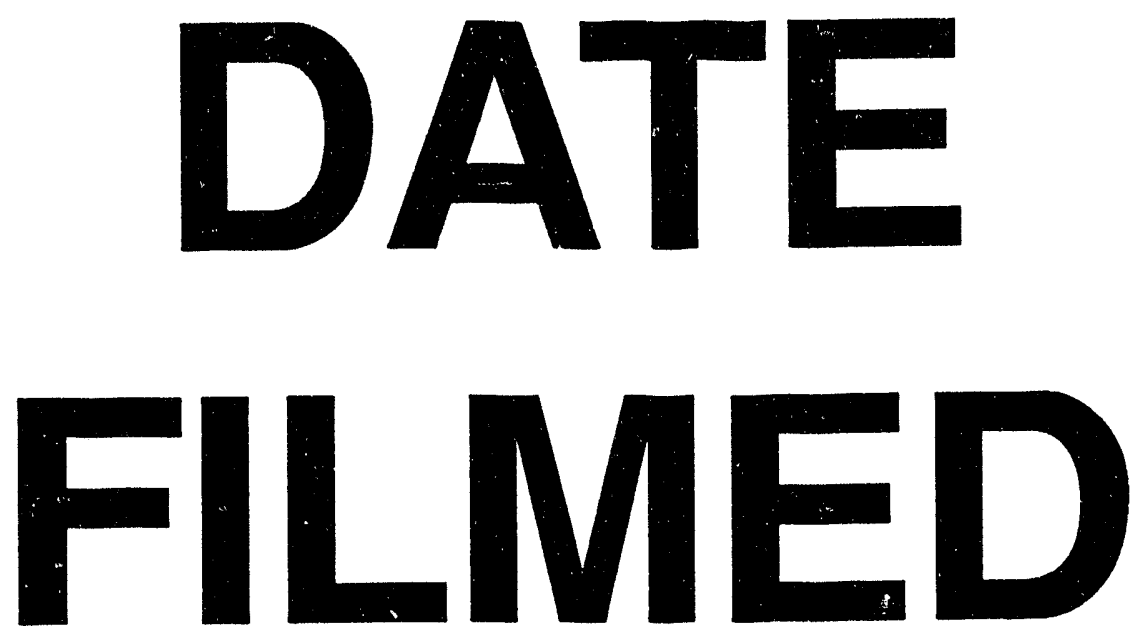

$6 / 22 / 94$
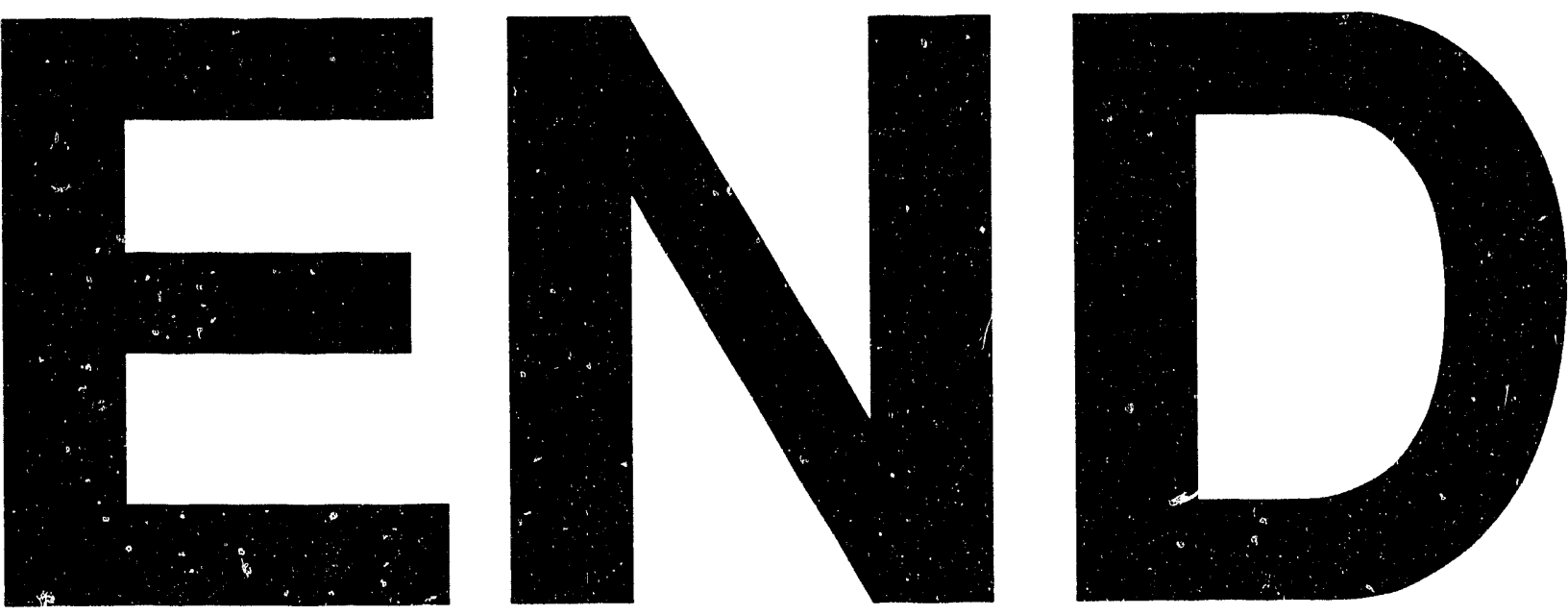
